\title{
Türkiye Yenilenebilir Enerji Kapasitesi Devreye Alma İşleminin Darboğaz Analizi
}

\author{
Muhammed Mustafa IZGEÇ ${ }^{1^{*}}$ \\ ${ }^{1}$ Enerji Piyasası Düzenleme Kurumu (EPDK), Ankara, Türkiye \\ *1izgec.mustafa@gmail.com
}

(Geliş/Received: 09/10/2020;

Kabul/Accepted: 05/04/2020)

Öz: Son yıllarda Dünyada olduğu gibi Türkiye'de de yenilenebilir enerji kaynaklarının kullanımına yönelim ivme kazanmıştır. $\mathrm{Bu}$ kaynakların üretime geçme sürelerinin uzun olduğu bilinmektedir. Çalışmanın amacı, santrallerin devreye alma süresi verilerini kullanarak detaylı bir analiz yapmak ve süreçlerde gerçekten sorun olup olmadığını tespit etmektir. Sorunların neler olduğu, başka bir çalışma konusu olarak önerilmektedir. Devreye alma sürelerinin hızlanması konusunda ise saha tecrübeleri göz önünde bulundurularak genel çözüm önerileri yapılmıştır. İrdelenen süreçler, tesisin devreye alınmasına kadar olan süreçlerdir ve işletme koşulları ile ilgili bilgi içermemektedir. Ayrıca; çalışmada ticari bilgi kabul edilecek veriler gölgelenmiş ve yorumdan kaçınılmıştır.

Anahtar kelimeler: Yenilenebilir enerji, yatırım süreçleri, enerji ekonomisi.

\section{A Bottleneck Analysis of Turkish Renewable Energy Capacity Commissioning}

\begin{abstract}
In recent years, the use of renewable energy sources has increased in the world and Turkey. Capacities using these resources are known to have a long turnaround time. The aim of the study is to make a detailed analysis using the commissioning time data of the power plants and to determine whether there are any problems in the processes. What the problems are is beyond the scope of this study and is proposed as another study topic. In order to prevent the delay in commissioning times, general solution suggestions were made considering the field experiences. The processes discussed are up to commissioning of the plant and do not contain information about operating conditions. Also; In this study, commercial data was shaded and interpretation was avoided.
\end{abstract}

Key words: Renewable energy, investment processes, energy economy.

\section{Giris}

Enerji, yaşamsal kaliteyi belirleyen en büyük ihtiyaç olarak karşımıza çıkmaktadır. Öyle ki, artık yaşam standartlarının seviyesi, kişi başı enerji tüketimi ile doğru orantılı olarak değerlendirilebilmektedir [1]. Şekil 1'de Uluslararası Enerji Ajansı (International Energy Agency-IEA) verilerine göre ülkelerin kişi başı ortalama enerji tüketimleri verilmiştir [2]. Türkiye, gelişmekte olan bir ülke olarak giderek daha fazla enerji gereksinimi duymakta ve giderek daha fazla enerji üretimi yapmaktadır.

Enerji yatırımları yapılırken devletlerin Enerji Politikaları, finansman seçenekleri, vergi ve teşvik oranları, geri dönüş süreleri, istihdam miktarı vb. değerlendirilmesi gereken birçok sosyo-ekonomik kriterin yanı sıra kaynağa yakınlık, teknoloji mevcudiyeti, teknoloji transfer seçenekleri, teknik işletme kapasitesi vb. teknik kriter de bulunmaktadır. Enerji yatırımlarında başarı, bütün bu dinamiklerin yönetilme becerisinin bir göstergesi olmaktadir.

Türkiye'de enerji ihtiyacını gösteren en önemli gösterge olan elektrik tüketimi, Enerji Piyasası Düzenleme Kurumu (EPDK) verilerine göre özellikle 2000 yılı sonrasında ciddi bir artış göstermiş̧tir [3]. Grafik incelendiğinde 2012 yılı sonrasındaki eğimin daha dik olduğu ve kapasitenin gelişim ivmesinin arttığı görülebilir (Şekil 2) . Bir diğer grafik 2000’ li yılların başında itibaren yenilenebilir kurul gücündeki artışı göstermektedir. Görüldüğü üzere toplam kapasitenin gelişime paralel olarak, rüzgar santralleri başta olmak üzere, yenilenebilir kaynaklı üretimde büyük bir kapasite artışı söz konusudur (Şekil 3) [4]. Bu da kapasitenin artışında, küresel fosil yakıt rezervlerin azalması ve çevresel kaygılar bu konuda ön plana çıkmaktadır [5]. Yenilenebilir kaynaklı üretimin sisteme dâhil olması süreci, 5346 sayılı Yenilenebilir Enerji Kaynaklarının Elektrik Enerjisi Üretimi Amaçlı Kullanımına İlişkin Kanun ile hız kazanmıştır. Bu kanun; "Yenilenebilir enerji kaynakları (YEK): Hidrolik, rüzgâr, güneş, jeotermal, biyokütle, biyokütleden elde edilen gaz (çöp gazı dâhil), dalga, akıntı enerjisi

\footnotetext{
${ }^{*}$ Sorumlu yazar: izgec.mustafa@gmail.com Yazarları ORCID Numarası: ${ }^{1}$ 0000-0002-6317-9250
} 
ve gel-git gibi fosil olmayan enerji kaynaklarını," şeklinde tanımlayarak konuya bir açıklık getirmiştir [6]. Bu kanunda yer alan ve sektöre ivme kazandıran en önemli yaklaşım, kaynak bazlı sabit fiyat öngören Yenilenebilir Enerji Kaynakları Destekleme Mekanizması (YEKDEM)' dır.

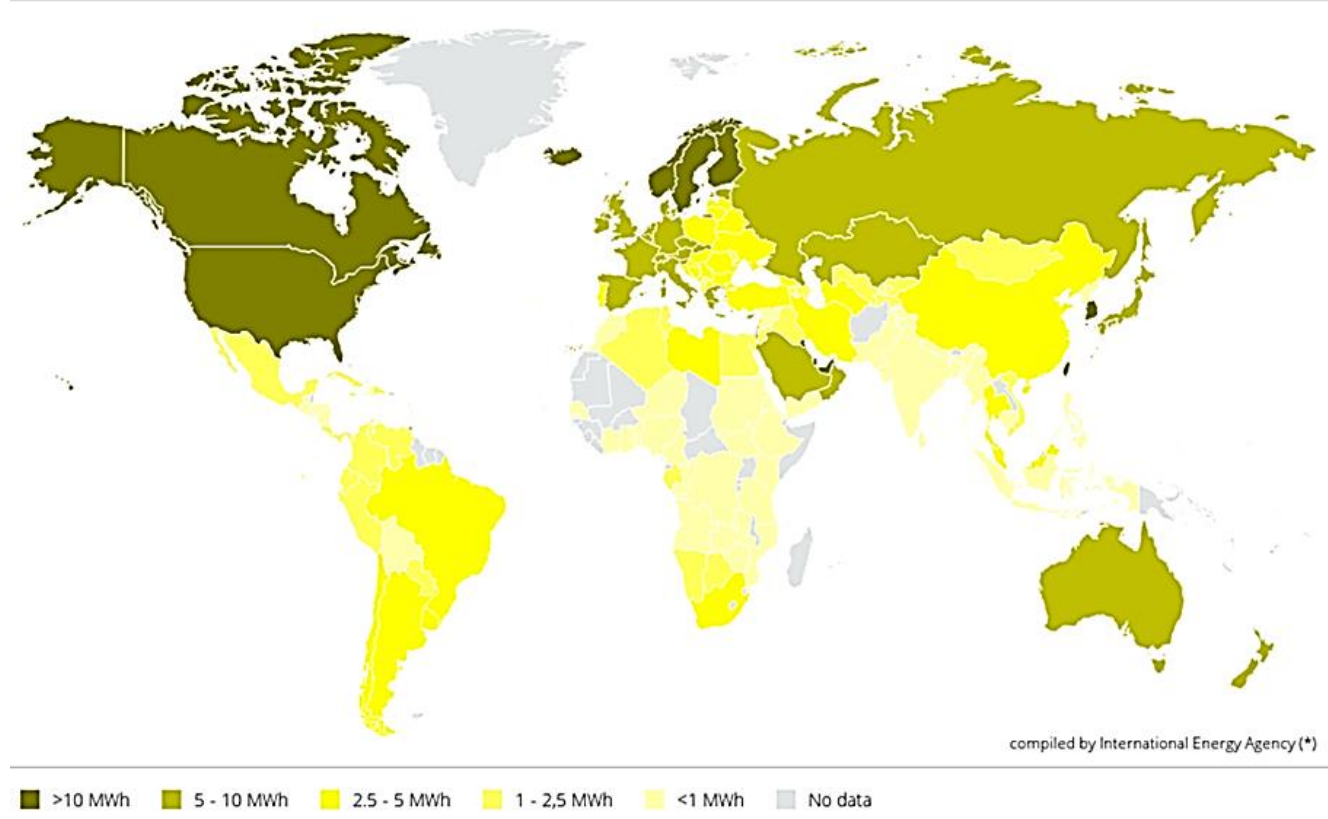

Şekil 1. Dünya kişi başı enerji tüketimi [2]

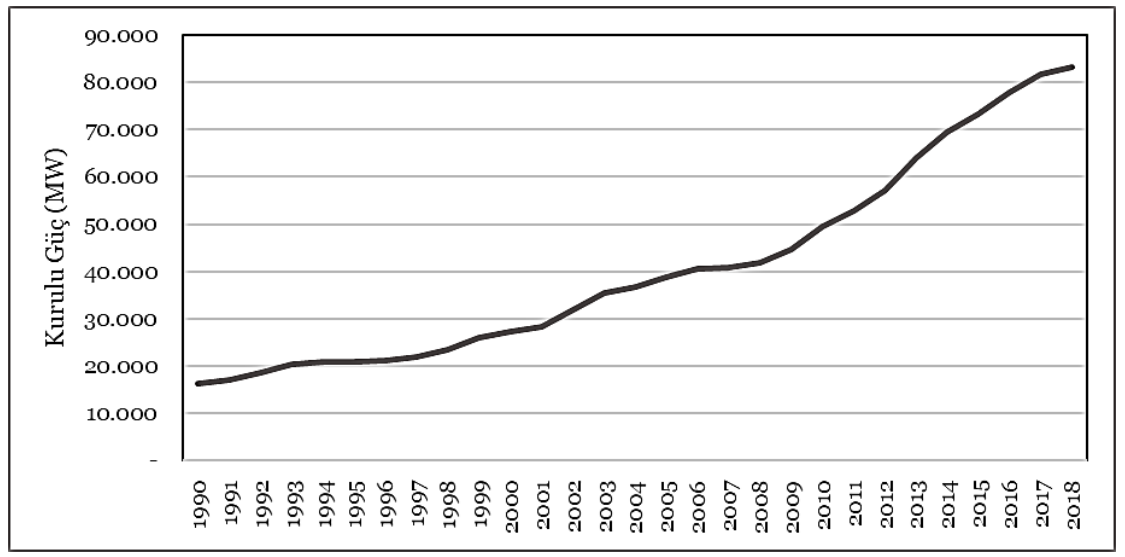

Şekil 2. Dünyada kişi başına düşen enerji tüketimi (Yıllık) (EPDK, 2019)

Yenilenebilir enerji yatırımlarının yönetimindeki önemli aşamalardan biri de Elektrik Piyasasında Lisanssız Elektrik Üretimine İlişkin Yönetmelik’tir. Bu yönetmelik ile 1MW altındaki kapasiteleri lisanstan muaf tutarak, daha az bürokratik işlemle, daha kısa sürede devreye alınması amaçlanmıştır [7].

Yenilenebilir kapasitenin ciddi şekilde artış gösterdiği yıllar içinde dahi izin süreçlerindeki atalet ve prosedür fazlalığı, bu konudaki talep ve şikâyetlerin dillendirilmesine ve çözüm önerilerine konu olmuştur. 7.Türkiye Rüzgâr Enerjisi Kongresi’nde özel bir oturum ile izin süreçlerinin sadeleştirilmesi üzerine öneriler değerlendirilmiştir [8]. Lisans ve izin prosedürünün sadeleştirilmesi çalışmaları, yeni bir yönetmelik ile şekil kazanmış ve daha hızlı devreye girecek daha büyük kapasitelerin önü açılmışıı. Çalışmanın amacı, devreye alma süresinde yaşanabilen aksaklıkların derecesini anlayabilmek, bu aksaklıkların etkilerini veriler üzerinden inceleyerek nedenlerini tespit etmek ve bu nedenlere ilişkin çözüm önerileri getirmektir. 


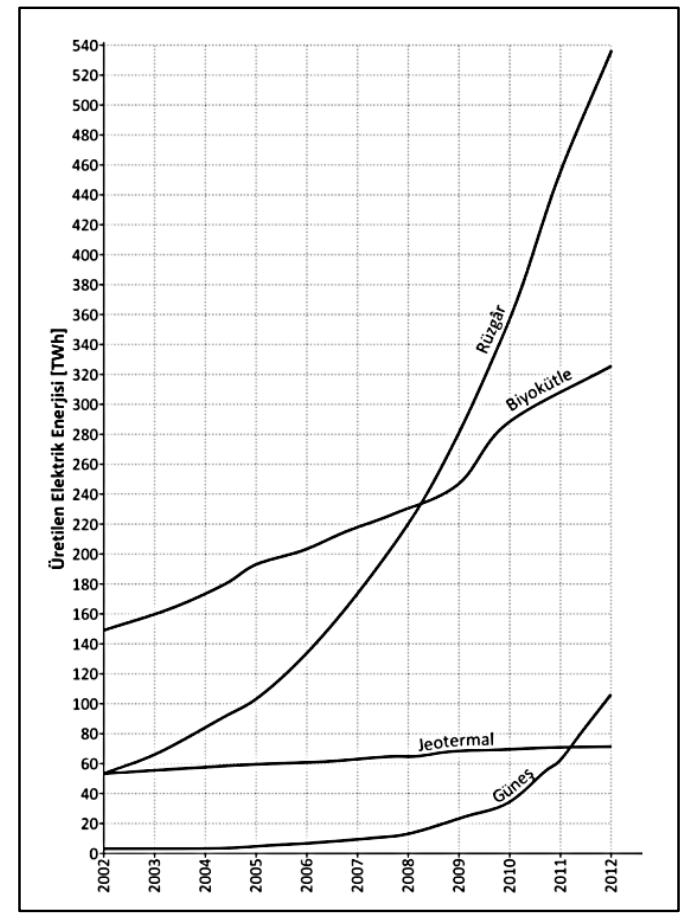

Şekil 3. Yenilenebilir kaynaklardan elektrik enerjisi üretiminin değişimi (hidroelektrik hariç)

\section{Literatürün Gelişimi}

Yenilenebilir enerjinin desteklenmesi konusunda son on yılda ciddi gelişmeler yaşanmıştır. Özellikle teknolojinin gelişimi ile birlikte düşen maliyetler sonrasında bütün bu gelişmeler hızlı bir şekilde kapasiteyi yenilenebilir kaynakların lehine evriltecek gibi görünmektedir. Yine de yenilenebilir enerji kullanan üretim kaynaklarının desteklenmesi, bu sürecin daha hızlı şekilde hayata geçmesine yardımcı olabilir. Destekleme mekanizmaları ve sürdürülebilir yapılar hakkında birçok akademik yayın bulunmaktadır. Abdmouleh, Alammari ve Gastli, çalışmalarında [9] yenilenebilir enerji kaynaklarına dayalı elektrik enerjisi üretimindeki gelişimin pazardaki teknolojinin mevcut durumu, finansman için mevcut bütçe, yenilenebilir enerji ile ilgili hedef ve ülkenin çevresel koşullarının etkisi yönünden değerlendirilmesi gerektiğini savunmuşlardır. Onlara göre destekleme mekanizmalarını oluştururken kaynak tipi veya teknoloji bakımından tekel oluşturmamak önemlidir. Haas ve diğerleri çalışmalarında [10] AB ülkelerinde yenilebilir enerji destekleme mekanizmalarını teker teker tanımlamışlar ve hangi destekleme mekanizmasının en etkin olduğunu tespit etmeye çalışmışlardır. Son derece ayrıntılı incelemelerin yapıldığı çalışmada destekleme çeşitleri bambaşka bir şekilde sınıflandırılmıştır. Buna göre:

- $\quad$ Fiyat desteklemesi düzenlemeleri: Bunlar kapasite veya enerjiye karşılık yapılır.

- Yatırım odaklı: Kapasite başına yatırım teşviki, hibe ve vergi kredisi şeklindedir.

- Üretim bazlı: Üretilen enerji başına olan tarifeli veya performanslı yaklaşımlarıdır.

- Miktar desteklemesi düzenlemeleri: Yenilenebilir enerjinin istenilen hedefi tutturması amaçlı stratejilerdir.

- İhale sistemi: Hangi sürede ne kadar yatırımın geleceği kesindir.

- Satılabilir sertifika sistemi: Piyasadaki faaliyetin kontrol altında olması anlamına gelir.

- Gönüllü yaklaşımlar: Bu yaklaşımlarda tüketicilerin küresel ısınmaya duyarlılığı nedeniyle gönüllü destek vermesi beklenir.

- Yatırım odaklı: Yatırıma hissedar, etik programlar vb.

- Üretim bazlı: Yeşil enerji tarifeleridir.

- Dolaylı stratejiler:

- Konvansiyonel olmayan üretim kaynaklarından alınan çevre vergileri

- $\mathrm{CO} 2$ emisyon vergileri/cezalar1

- $\quad$ Fosil yakıt ve nükleere verilmeyen teşvikler. 
Becker ve Fischer'a göre [11] yenilenebilir enerjinin maliyeti uzun dönemde daha fazla olmasına rağmen etki ettiği sosyal, ekonomik, çevresel ve sağlık alanlarındaki etkilerini matematiksel olarak tahmin etmenin güçlüğünden ötürü uzun dönemdeki karlılı̆ğnı ispatlamak oldukça güçtür. Tarife ve ihale bazlı sistem temelde aynı olmasına rağmen yalnızca ödeme şeklinin nasıl hesaplandığı ile ilgili bir farklılık bulunmaktadır. Becker ve Fischer, teknoloji, destekleme periyodu, alım garantisi gibi birçok kriterin tarife bazlı yaklaşımı birçok farklı şekli varmış gibi gösterdiğini ancak hepsinin aslında en temel destekleme olduğunu savunmaktadır.

Schallenberg ve Rodriguez çalışmalarında [12] tarife bazlı destekleme mekanizmalarını en yaygın ve en etkin destekleme mekanizmaları olarak tanımlamıştır. Bu mekanizmaların dezavantajlarından biri, sisteme yüklediği maliyetlerdir. $\mathrm{Bu}$ maliyetleri azaltmak için uygulanan taban ve tavan fiyat uygulamalarının kullanıldığı görülmektedir. Bu uygulama ise iki avantaja sahiptir:

1-Sistemi yenilenebilir enerji santralleri açısından daha güvenli kılmaktadır.

2-Santralleri, piyasada faaliyet göstermek konusunda çekincelerden kurtarmaktadır.

Yaptıkları analizlere göre saatlik bazlı taban-tavan fiyat uygulamaları yerine aylık veya yıllık bazlı tabantavan fiyat uygulamalarının daha verimli olduğunu değerlendirmişlerdir.

Uluslararası literatürde incelen konuya 1şık tutabilecek çok sayıda çalışma olmakla birlikte ulusal literatürde konuya ilişkin kaynaklar oldukça sınırlıdır. İzgeç, çalışmasında [13] yenilenebilir kaynak alanı senaryoları ve finansman modelleri üzerine senaryolar ortaya koymuştur. Bu çalışmaya göre kaynak alanları yaklaşımı, tutarlı ve yenilikçi bir destekleme senaryosudur. Şimşek, H.A ve Şimşek, N çalışmalarında [14] yenilenebilir enerjiye yönelimin ve bu konuda teşvik senaryoları üretmenin küresel bakışla aynı doğrultuda hareket etmek olduğuna değinmişlerdir. Ertürk çalışmasında [15] YEKDEM fiyatları ve ortalama verimlilik parametreleri üzerinden rüzgâr potansiyelinin ekonomik analizini yapmış ve $13.600 \mathrm{MW}$ değerindeki bir rüzgâr kapasiteyi ekonomik olarak gerçekleştirilebilir bulmuştur. Özcan ise çalışmasında [16] katılımcıların teşvik mekanizmasına bakışını tespit etmeye çalışmıștır. Özcan'a göre yerli katkı teşviki oldukça önemli bir öneridir. Diğer taraftan yenilenebilir enerji kullanan santrallerin proje aşamasındaki devreye alma süresinin hafifletilmesi ve onay alınan taraf sayısının azaltılması veya tip projeler, önemli bir teşvik olarak görülebilecektir. Çalışma sonuçlarına göre katılımcılar, teşvik fiyatlarının sürdürülebilir olduğunu değerlendirmektedir.

\section{Yöntem}

Türkiye'deki yatırım çalışmalarının lisanslı projeler için önlisans tarih, lisanssız projeler içinse çağrı mektubunun alındı ̆̆ 1 tarihten işletmeye girene kadar olan sürecini değerlendirmek için verilerin analiz edilmesi, olası darboğazları gösterebilir. Bu amaçla 2012-2019 yılları arasında ön lisans veya çağrı mektubu almış ve devreye girmiş olan santraller kaynak bazına, kapasite büyüklüğüne, bağlı bulunduğu dağıtım şirketine göre analize tabi tutulacak ve normal dağılım grafikleri istatistiksel yöntemler kullanılarak analiz edilecektir. Bu çalışmada kaynak bazında tüm santraller kullanılmamıs elde edilen veri havuzundaki santrallere ilișkin veriler kullanılmıștır. Analizde MS Excel, SPSS ve SQL Server özellikleri kullanılmıștır. Temin edilen veriler arasında çağrı mektubu tarihi belli olmayan santraller kullanılmamıștır. 6545 santral üzerinde incelemeler yapılmıştır. Santrallerin kurulu güçleri 1,5-12900 kW aralığındadır. Kaynak tipine göre Biyoenerji Santrali (BES), tri/kojenerasyon santrali (3gen), Rüzgâr Enerjisi Santrali (RES) ve Güneş Enerjisi Santrali (GES) verileri kullanılmıştır. Çağrı mektubu tarihi ile kabul tarihi arasındaki süre "gün sayısı" olarak adlandırılmış ve analizler bu terim üzerinden yapılmıştır. Analizde ticari kaygılara neden olabileceği düşüncesi ile santral ismi ve dağıtım bölgesi isimleri gölgelenmiştir. Kaynak, dağıtım şirketi, kapasite bazlı analizlerde ortalama gün sayısı üzerinden hesaplamalar yapılmıştır. Bu hesaplamalar yapılırken; Elektrik Piyasasında Lisanssız Elektrik Üretim Yönetmeliği’ nde yer alan geçici kabul tamamlama tarihleri göz önüne alınmıştır. İlgili yönetmelik maddesi;

Üretim tesislerinin işletmeye girmesi ve sistem kullanımı

MADDE 19 - (1) Bu Yönetmelik hükümlerine göre şebekeye bağlanacak üretim tesislerinin geçici kabul işlemlerinin, bağlantı anlaşmasının imza tarihinden itibaren;

a) OG seviyesinden bağlanacak hidrolik kaynağa dayalı üretim tesislerinde üç yll,

b) OG seviyesinden bağlanacak hidrolik kaynağa dayalı üretim tesisleri dışındaki üretim tesislerinde iki yıl,

c) AG seviyesinden bağlanacak tüm üretim tesislerinde bir yll,

c) Illetim şebekesine bağlanacak üretim tesislerinde 2/11/2013 tarihli ve 28809 sayll Resmî Gazete'de yayımlanan Elektrik Piyasası Lisans Yönetmeliği çerçevesinde aynı niteliklere sahip üretim tesisleri için öngörülen süre,

içerisinde tamamlanması zorunludur. Elektrik Piyasası Lisans Yönetmeliğinin 35 inci maddesinde belirtilen mücbir sebepler ve Kurul tarafindan uygun bulunan haller dıșında, bu sürelerin sonunda üretim tesisinin 
tamamlanmaması halinde bağlantı anlaşması, tahsis edilen kapasite, teknik etkileşim izni ile su kullanım haklarına ilişkin izin belgeleri kendiliğinden hükümsüz hale gelir, hükümlerini içermektedir.

\section{Analiz}

Şekil 4'te yer alan radar grafikte görüleceği üzere 6545 santral üzerinde yapılan analizde örneklem içindeki en kısa gün sayısını 14, en uzun gün sayısının ise 1643 gün olduğu tespit edilmiştir. Ortalama kabul süresi 776 gün iken standart sapma, 254 olarak hesaplanmıştır. Kapasite büyüklüğü ile gün sayısı arasında korelasyon araştırılmış ve 0,13 katsayısı elde edilerek sıfıra çok yakın olduğundan ilişkisiz bulunmuştur.

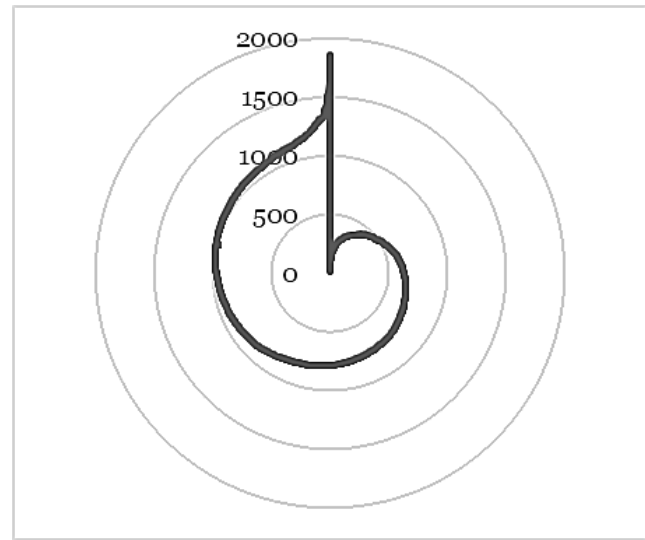

Şekil 4. Santrallerin (6545) gün sayısına göre küçükten büyüğe sıralanışı

Kaynak tipine göre yapılan analizlerde ortalama değerler kullanılarak 4 tip santral (BES, 3gen, RES ve GES) incelenmiştir. Kaynak tipine göre en hızlı BES iken en yavaş RES olmuştur. Ortalama kabul süresi 682 gün ve standart sapması 187'dir. BES ve RES kurulum süreleri arasındaki bu fark, BES'lerin kurulduğu alanların kamulaştırma ve mülkiyet edinimi noktasında daha hızlı işlemlere tabi alanlar olması ve yakınlarında sisteme bağlantı noktası olarak daha fazla alternatif olmasından kaynaklı olduğu görülmüştür. Hızlı kamulaştırma ve daha kısa ve avantajlı bağlantı noktası ve hat tesisi bu kaynak tipinin daha çabuk üretime hazır hale gelmesi yönünde bir avantajdır. RES'lerde ise, her bir rüzgâr üretim türbinin saha içinde en uygun şekilde konumlandırılması gereklidir. Bu türbinlerin dağınık olması ve geniş bir alanı kaplaması sebebi ile kamulaştırma ve arazi edinim süreçleri uzamaktadır. Yerleşim yerlerinden uzaklığı nedeni ile sistem bağlantı noktası kısıtı ve hat uzunlukları gibi etkenlerle tesis tamamlama süreleri uzayabilmektedir. Genellikle yerleşim yerleri dişına tesis edilen bu tip santraller ormanlık arazide konuşlandırdıkları takdirde orman kesim ve kullanım izinleri çerçevesinde de zaman kaybı yaşanabilmektedir (Şekil 5).

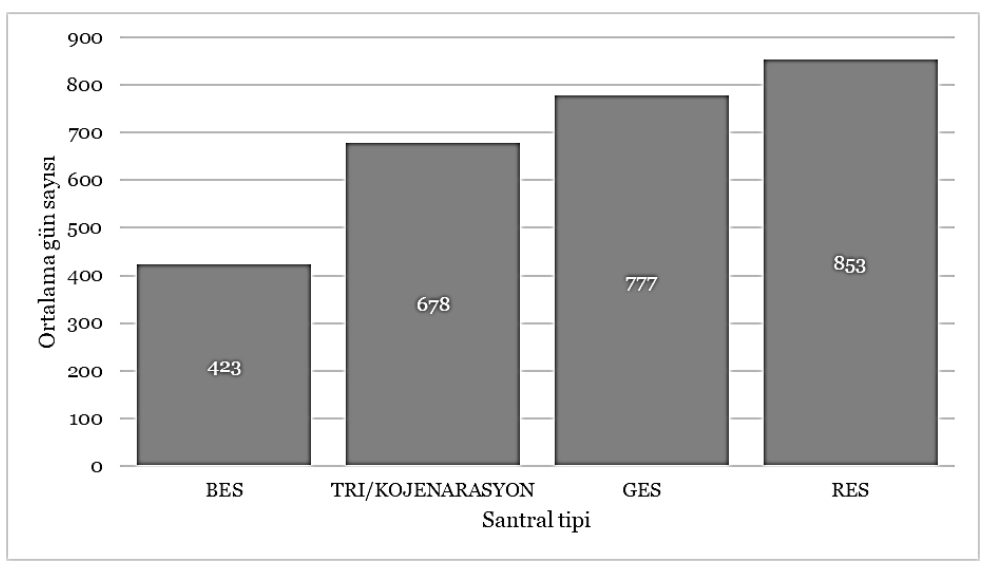

Şekil 5. Kaynak tipine göre ortalama gün sayısı 
Dağıtım bölgelerine göre yapılan analizde 80 bölge analiz edilmiştir. Bölgeler arasında Organize Sanayi Bölgesi (OSB) ve Elektrik Dağıtım Şirketleri (EDAŞ) yer almıştır. En hızlı kabul ortalaması 49 gün; en yavaş olanı 963 gün olmuştur. Yalnızca EDAŞ'lar için yapılan analizde en düşük gün ortalaması 388, en yüksek 863, ortalama 708 gün olmuştur. İllere göre 74 il üzerinden analiz yapılmış, en hızlı kabul ortalaması 225, en yavaş 1184 gün olarak hesaplanmıştır. Ortalama gün sayısı 744 gün, standart sapma 183'tür. Bölgeler arasındaki değişkenlik gösteren bu sürelere, ekipman ve teknik eleman yetersizliği, coğrafya ve iklim koşulları, yerel yönetimler arasındaki uygulama farklılıkları başlıca nedenler olarak gösterilebilir. Üretim tesisinin kurulacağı illerde, izin süreçlerinde yer alan kamu kurum ve kuruluşlarının teşkil yapısı da süreçlerin uzamasında etken olabilmektedir (Şekil 6 ve Şekil 7).

Kapasite büyüklüğüne göre 499 farklı kapasite analiz edilmiştir. En hızlı 80, en yavaş 301 gün ortalama değerine ulaşılmıștır. Ortalama gün sayısı 212 olurken kapasite büyüklüğü ile kabul süresi arasında korelasyon araştırılmış ve ilişkisiz bulunmuştur. Genel algının aksine bir santralin devreye alınma süresi ile kapasite büyüklüğü arasında doğrudan bir ilişki olmaması, kapasiteden bağımsız olarak kaynak bazlı tip onay ve izin sürecinin devreye alma süreçlerini hızlandırabileceğine bir işaret olarak görülebilir. Süreç yönetimine ilişkin yapılacak düzenleme ve tipleştirme yaklaşımları ile daha kısa sürede daha büyük kapasiteler üretime hazır hale gelebilecektir (Şekil 8).

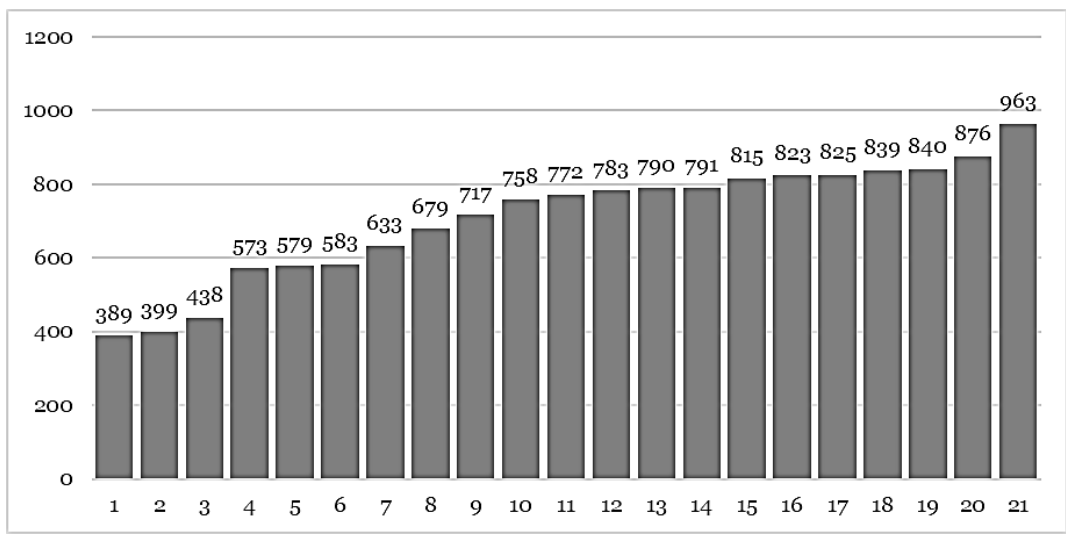

Şekil 6. EDAŞ ortalama gün sayıları

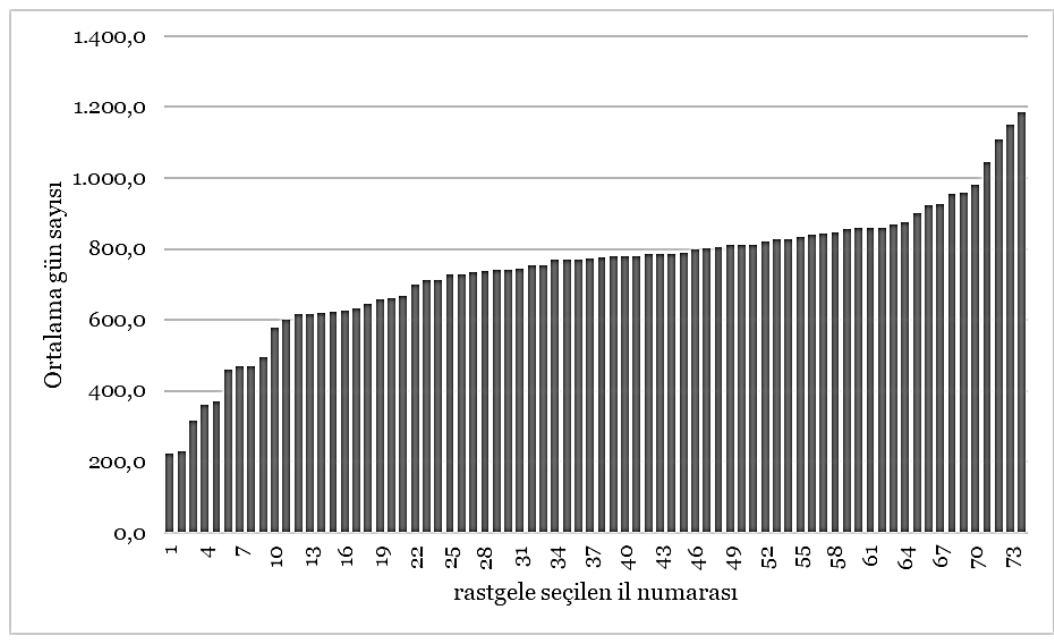

Şekil 7. İllere göre ortalama gün sayısı

GES'ler üzerinde yapılan araştırmada 6394 santral verisi incelenmiştir. En hızlı süre 14 gün olurken en yavaş süre 1895 olarak görülmüştür. Ortalama süre 777 olmuştur (Şekil 9). GES özelinde de kapasite ile kurulum süresi arasında bir ilişki ortaya çıkmamıştır. Bu sonuç tüm kaynak tipleri için geliştirilen yaklaşımla uyumludur. 
Muhammed Mustafa İZGEÇ

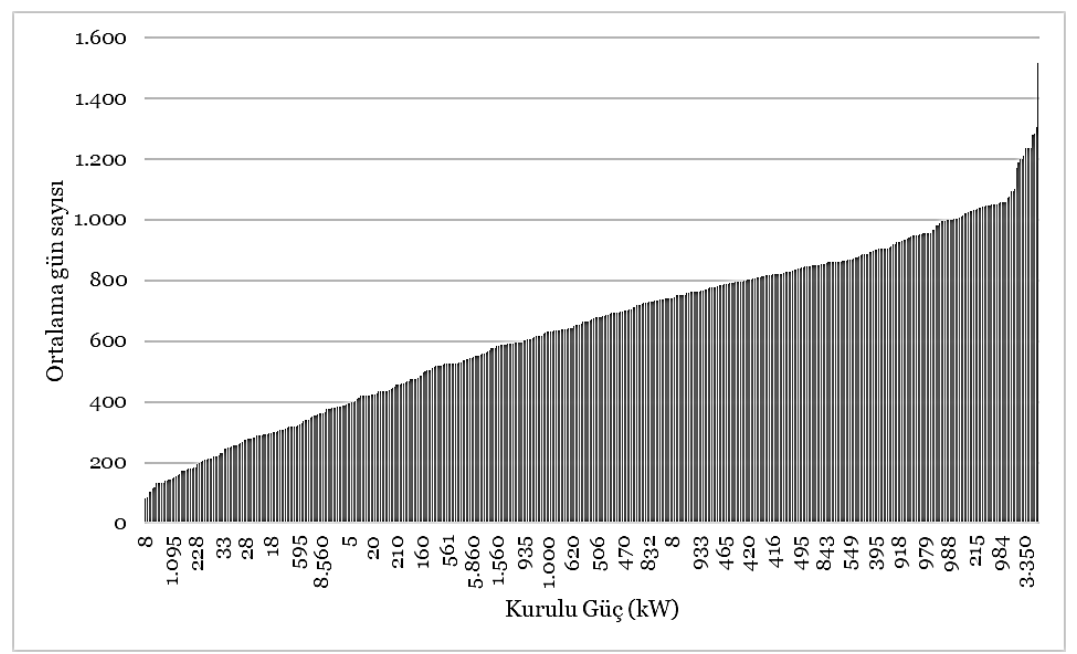

Şekil 8. Kapasite büyüklüğüne göre ortalama gün sayısı

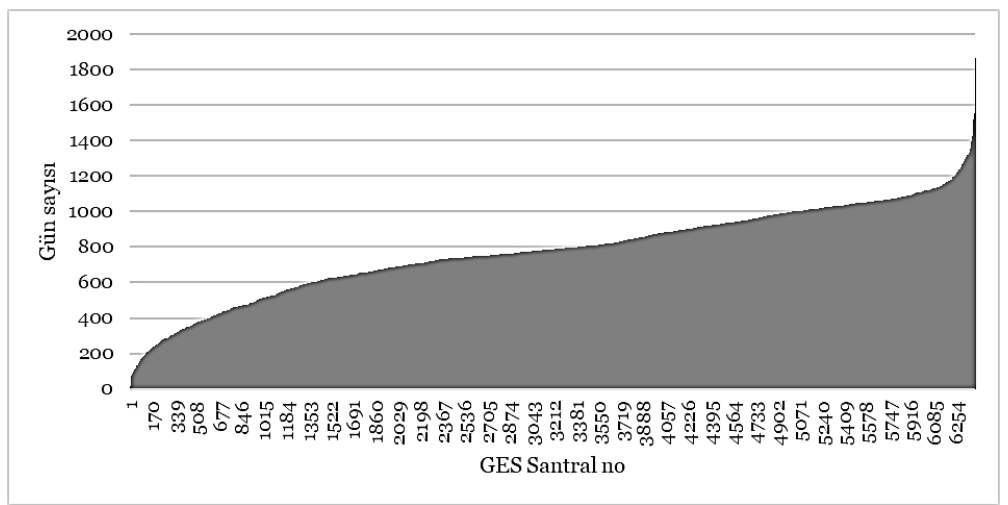

Şekil 9. GES için ortalama süreler

GES için EDAŞ performanslarına bakıldığında en düşük ortalamanın 300, en yüksek 970 gün olduğu ve ortalamanın 696 gün olduğu görülmektedir. Aynı kaynak tipi için bile dağıtım şirketleri bazında farklılıklar oluşması uygulama birlikteliği anlamında süreçsel sıkıntıları teyit etmektedir. Ancak dikkat edilmesi gereken husus dağıtım şirketlerinin süreçleri kadar yerel yönetim süreçleri ve coğrafyanın da bu süreçlere etki ettiğidir (Şekil 10).

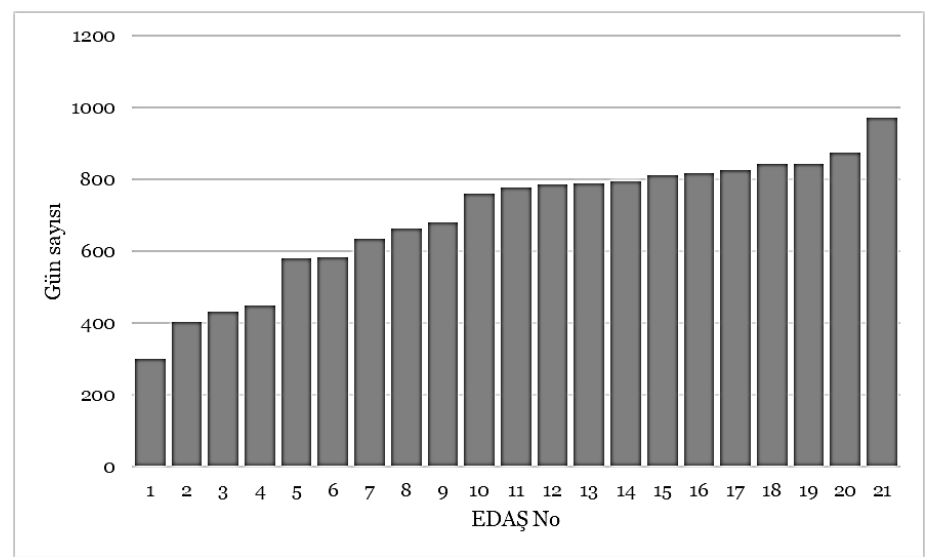

Şekil 10. GES için EDAȘ ortalama gün sayısı 
Analiz aşamasında geciken yatırımların $\mathrm{CO}_{2}$ eşdeğerinin ve mali karşılı̆̆ının hesaplanması ayrıca önem taşımaktadır. Bu tip bir değerlendirmeyi yapabilmek için 3 gen, BES, RES ve GES kaynakların devreye girememiş toplam kapasitesinin üretebileceği elektriği hesaplamak gerekmektedir. Tablo 1'de santral tiplerinin toplam kurulu gücü verilmektedir. Tablo 2 ise santrallerin devreye girmesi için gerekli gün sayısı için analiz sonuçlarını göstermektedir. Tablo 1 ve Tablo 2 verilerini kullanarak devreye girecek kapasitenin gecikmesi nedeniyle kullanılan farklı kaynağa ödenen bedel ve bu kaynakların çevreye etkisi hesaplanmak istenirse, ortalama verimlilik, ortalama elektrik fiyatı ve elektriğin kaynaklara göre $\mathrm{CO}_{2}$ salınım etkisinin bilinmesi gerekir. Ömürgönülşen ve arkadaşlarının çalışmasında [17] verimli rüzgâr kapasitenin \%40 kabul edildiği araştırılmıştır. EPİAŞ verilerine göre [18] örneklem aralığındaki ortalama piyasa fiyatı $171 \mathrm{TL} / \mathrm{MWh}$ olmuştur. Doğalgaz kullanılarak yapılan elektrik üretiminin $\mathrm{GWh}$ başına $\mathrm{CO}_{2}$ salınımı 499 ton olarak kayıtlıdır [19].

Tablo 1. Santral Tiplerinin Toplam Kurulu Gücü (EPDK-2019 yılı itibarı ile)

\begin{tabular}{|l|l|}
\hline Santral Tipi & Toplam Kurulu Gücü (kWe) \\
\hline BES & 41.641 \\
\hline GES & 5.310 .806 \\
\hline RES & 68.078 \\
\hline 3/Kojenerasyon & 165.426 \\
\hline
\end{tabular}

Tablo 2. GES için EDAŞ ortalama gün sayısı

\begin{tabular}{|c|c|c|c|c|}
\hline \multirow{2}{*}{ Siralama ölçütü } & \multicolumn{4}{|c|}{ Gün Sayı1s1 } \\
\hline & Ortalama & En küçük & En büyük & St.Sapma \\
\hline 6545 santral & 776 & 14 & 1865 & 255 \\
\hline Kaynak tipine göre & 682 & 423 & 853 & 187 \\
\hline Dağıtım OSB - EDAŞ & 540 & 49 & 963 & 197 \\
\hline EDAŞ & 700 & 388 & 863 & 161 \\
\hline İllere göre & 744 & 225 & 1184 & 184 \\
\hline 3 gen & 678 & 231 & 1210 & 284 \\
\hline BES & 422 & 125 & 1212 & 290 \\
\hline RES & 852 & 116 & 1643 & 370 \\
\hline GES & 251 & 14 & 1865 & 252 \\
\hline GES-EDAŞ'lara göre & 696 & 300 & 970 & 178 \\
\hline GES-illere göre & 750 & 225 & 1184 & 176 \\
\hline
\end{tabular}

\section{Değerlendirmeler}

Türkiye'de yenilenebilir enerji santrallerinin (trijenerasyon, biyoenerji, rüzgâr ve güneş) çağrı mektubu ile geçici kabul tarihi arasındaki ortalama süre 776 gündür ( 2 yıl). Trijenerasyon ortalaması 678, BES ortalamas1 422, RES ortalaması 852 ve GES ortalaması 251'dir. Buna göre en hızlı devreye giren kapasite GES kapasitedir. Devreye alınma işlemi en uzun süren kapasite RES kapasitedir.

OSB ve EDAŞ’tan oluşan dağıtım şirketlerinin ortalama devreye girme süresi 540 iken yalnızca EDAŞ’lar için bu süre 700 gündür. Buna göre EDAŞ'lar OSB'lere göre çok daha yavaş işlem yapmaktadır.

RES ve GES için en uzun devreye grime süresi çok yüksektir (1643 ve 1865 gün). Ancak; GES standart sapmasının daha küçük olması, ortalamadan sapma yoğunluğunun daha az olduğunu göstermektedir. Dolayısıyla, GES işlemlerinin RES işlemlerine göre kolaylığı bulunmaktadır. Lisanssız üretim santrallerinin ağırlıklı olarak GES olduğu düşünüldüğünde bu sonuç beklenmektedir ve kolaylaştırıcı önlemlerin karşılık verdiği anlamına gelmektedir. 
GES'lerin EDAŞ'lara göre değerlendirmesinde ortalama devreye girme süresi 696 gündür. GES'ler için 251 ve EDAŞ'lar için 700 olan bu ortalamaya göre net şekilde belirli dağıtım şirketinde problemlerin yoğunlaştığ 1 söylenemez. EDAŞ prosedürlerinin yavaşlığa neden olduğu ve ortalama olarak her bölgede aynı oranda yavaşlattığı söylenebilir. Oysa standart sapmalara bakıldığında en düşük değer EDAŞ ortalamalarındadır. Bunun anlamı, özellikle bazı EDAŞ'lar çok daha kolay ve çok daha zor yönde tutum sergileyebilmektedir. Bu sonuca göre EDAŞ'ların bulunduğu bölgelerdeki diğer onay mercilerinden kaynaklı süre uzamalarının da daha sistematik şekilde araştırılmasında fayda görülmektedir.

GES'lerin illere göre değerlendirmesinde ortalama devreye girme süresi 750'dir. Tüm örneklem için bu rakam 744 olmuştur. Tüm GES'ler için 251 değeri hesaplandığı hatırlanırsa, bazı illerde işlemlerin görece çok uzun sürdüğü anlaşılmaktadır. Haritada (Şekil 10) görüleceği gibi Bingöl, Ağrı, Şırnak, Van illerinde devreye girme nedenlerinin çok uzun sürdüğü hesaplanmıştır.

İllere göre devreye girme süresi ortalama 744 'tür. Buna göre bazı illerde işlemler daha uzun sürmektedir. Kaynak tipine göre devreye girme süresi ortalama 682 gün olarak hesaplanmıştır. Standart sapması, toplam santrallerin standart sapmasından küçüktür. Buna göre kaynak tipine göre ortalamalar birbirine daha yakındır.

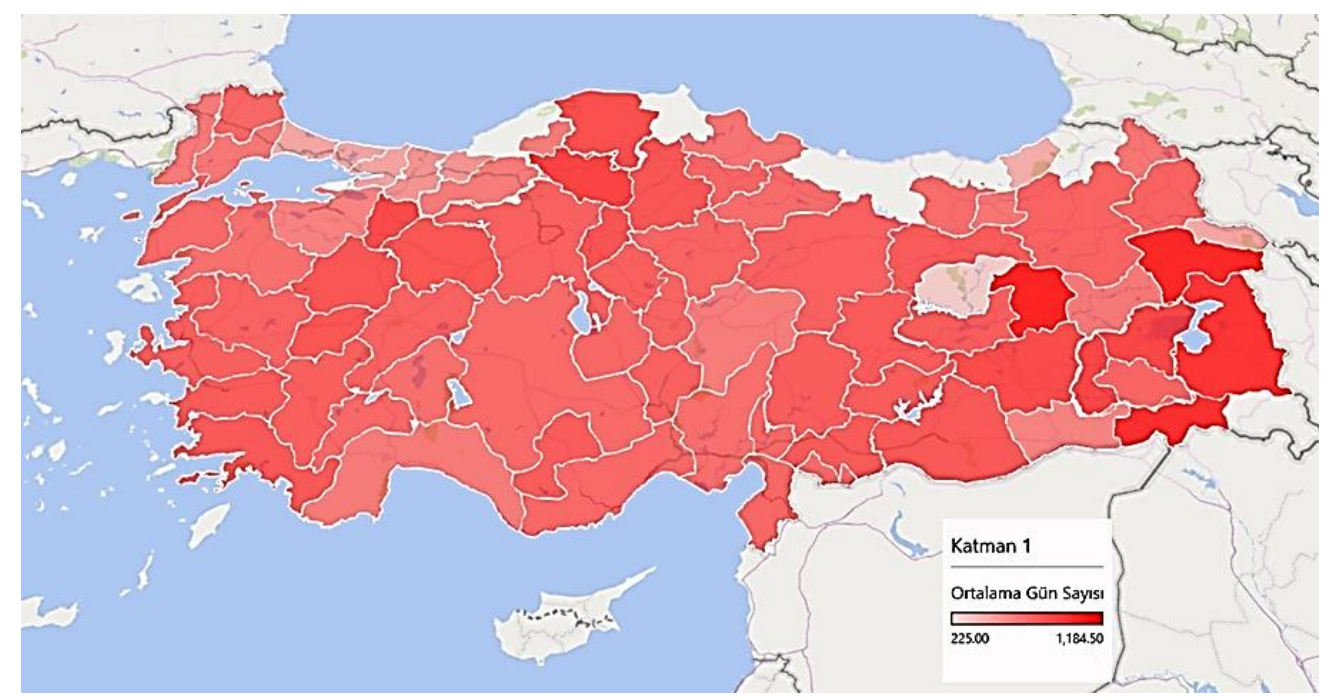

Şekil 11. GES devreye grime sürelerinin illere göre ortalamaları

\section{Sonuç}

Yapılan çalışmadan elde edilen sonuçlara göre; yenilenebilir enerji santralleri arasında en hızlı devreye alınan santraller GES'tir. Lisanssız Üretim Yönetmeliği ile onay prosedürünün sadeleştirilmesinin bu konuda etkili olduğu düşünülmektedir. RES için ortalamaların yüksek olması, devreye alma süresinde bu tip bir sadeleştirme yapılamamış olmasından kaynaklanmaktadır. Lisanssız Üretim Yönetmeliği uygulamalarının RES ve diğer yenilenebilir kapasiteyi de kapsamasına rağmen hem kaynağın karakteri hem teknolojinin bulunduğu seviye gereği GES kaynaklar bu avantajı daha iyi şekilde değerlendirmiştir. YEKA gibi alternatif bir destekleme mekanizmasının (onay süreçleri daha önceden tamamlanmış olan yöntem) analiz sonuçlarına büyük etki edeceği tahmin edilmekle birlikte henüz YEKA devreye alması gerçekleşmemiş olduğundan değerlendirmesi yapılamamıştır.

Dağıtım şirketlerine göre yapılan analizlerde EDAŞ onaylarının OSB onaylarına göre çok daha uzun sürdüğü anlaşılmıştır. Birkaç dağıtım şirketinde görece daha kısa ve daha uzun onay süreleri olduğu anlaşılmaktadır. Kısa olanın iyi uygulama örneği kullanılmalı; uzun olanın problemli olan alanları üzerine çalışmalar yapılmalıdır.

Analiz sonuçlarına göre yatırımın işletmeye girmesi için gecikmesi durumu, hem bu kapasiteye alternatif kapasitelerden kullanılan elektriğin maliyeti, hem doğaya kirletici etkileri anlamında büyük zararlara yol açmaktadır. Öyle ki, ortalama hesaplar üzerinden 2,5 milyar TL fosil yakıtlar ile üretilen elektrik için harcanmış ve karşılığında 7,3 milyon ton $\mathrm{CO}_{2}$ salınımına neden olunmuştur [19]. Bu zararların azaltılması için yatırımların mümkün olan en kısa sürede devreye alınmasının zaruriyeti, ortalama rakamlar üzerinden dahi net bir şekilde anlaşılmaktadır. 
İl bazında yapılan analizlerde bazı illerdeki onay prosedürünün oldukça ağır ilerlediği anlaşılmıştır. Bu durumun jeo-politik, sosyal, ekonomik, teknik vb. birçok nedeni olabilir. Kaynak nedenler araştırılmalı ve iyileştirme yöntemleri geliştirilerek otoriteye sunulmalıdır [5].

Analiz sonuçlarına göre Türkiye'de en hızlı devreye alınan santral için devreye alma süresi 14 gün iken en yavaş santral için devreye alma süresi 1865 gün olmuştur. Hem bu aralık çok fazladır; hem de standart sapması 255 görünen bu dağılımda sorunun münferit olmadığı anlaşılmaktadır. Buna göre devreye alma sürecine ilişkin iyileştirme çalışması yapılması önerilmektedir. Bu süreçlerin hızlandırılması için;

- Kaynak bazlı tip başvuruların oluşturulması,

- Yerel yönetimlere ilişkin prosedürlerin tek tip hale getirilmesi,

- Kurumlar arası ortak mutabakat gerektiren prosedürlerin entegre bir bilgi yönetim sistemi aracilığıyla yürütülmesi

- Tüm başvuruların ilgili kurumca bir süreç yönetimine tabi olması

- Kaynak bazlı fizibilite ve finansman modeli konusunun Kamu tarafindan ayrı bir birimle desteklenmesi, önerilebilir.

Yatırımın işletmeye geçmesine kadar olan süreçte onay prosedürleri kadar yatırım destek modellerinin doğru stratejiler ile hayata geçirilmesi ve bunun için de teknik, finansal ve işletme yönleriyle de araştırılmasının önem arz ettiği değerlendirilmektedir.

\section{Teşekkür}

Bu çalışmada kullanılan verilerin elde edilmesinde yardımcı olan Enerji Piyasaları İşletme A.Ş. çalışanlarına, verilerin derlenmesinde yardımlarından ötürü değerli arkadaşım Sayın Tamer Emre' ye teşekkür ederim

\section{Kaynaklar}

[1] Boardman B. Fuel Poverty: From Cold Homes to Affordable Warmth. London;New York;: Belhaven Press; 1991.

[2] IEA, EA Atlas of Energy, 0608 2019. [Çevrimiçi]. Available: http://energyatlas.iea.org/\#!/tellmap/-1118783123/1.

[3] EPDK, 2018 Yılı Elektrik Piyasası Gelişim Raporu, Ankara, 2019.

[4] Observer, EDF, Fondation Pour Le Monde, Worldwide electricity production from renewable energy sources, Stats and Figures Series, 1. Electricity production in the world: General forecasts, Fifteenth inventory, 2013 edition, http://www.energiesrenouvelables.org/observ-er/html/inventaire/pdf/15e-inventaire-Chap01-Eng.pdf.

[5] Karık F, Sözen A, İzgeç M . Rüzgâr Gücü Tahminlerinin Önemi: Türkiye Elektrik Piyasasında Bir Uygulama. Politeknik Dergisi. 2017; 20(4): 851-861.

[6] Resmi Gazete, Yenilenebilir Enerji Kaynaklarının Elektrik Enerjisi Üretimi Amaçlı Kullanımına İlişkin Kanun, Resmi Gazete, 2005.

[7] Resmi Gazete, Elektrik Piyasasında Lisansız Elektrik Üretimine İlişkin Yönetmelik, Resmi Gazete, 2013.

[8] TÜREK, 7.Türkiye Rüzgar Enerjisi Kongresi Raporu, Ankara, 2018.

[9] Abdmouleh, Zeineb, Rashid A. M. Alammari, and Adel Gastli. 2015. "Review of Policies Encouraging Renewable Energy Integration \& Best Practices." Renewable and Sustainable Energy Reviews 45: 249-262.

[10] Haas R, Panzer C, Resch G, Ragwitz M, Reece G, Held A. A historical review of promotion strategies for electricity from renewable energy sources in EU countries. Renewable and Sustainable Energy Reviews. 2011;15:1003-1034.

[11] Becker B, Fischer D. Promoting renewable electricity generation in emerging economies. Energy Policy. 2013;56:446455.

[12] Schallenberg-Rodriguez J. Renewable electricity support system: Design of a variable premium system based on the Spanish experience. Renewable Energy. 2014;68:801-813.

[13] Izgeç MM, Emre T, Sözen A, Ömürgönülşen M. Financial sustainability analysis of renewable energy plant applications. Energy Sources, Part B: Economics, Planning, and Policy. 2017;12:895-902.

[14] Simsek N, Simsek HA. Recent incentives for renewable energy in Turkey. Energy Policy. 2013;63:521-530..

[15] Ertürk M. The evaluation of feed-in tariff regulation of Turkey for onshore wind energy based on the economic analysis. Energy Policy. 2012;45:359-367.

[16] Ozcan M. Assessment of renewable energy incentive system from investors' perspective. Renewable Energy. 2014;71:425-432.

[17] Ömürgönülşen M, Emre T , Atıcı K . Türkiye'deki Rüzgar Enerjisi Santrallerinin Göreli Etkinliklerinin Veri Zarflama Analizi ile Ölçümü. Hacettepe Üniversitesi İktisadi ve İdari Bilimler Fakültesi Dergisi. 2016; 34(2): 79-96.

$\begin{array}{llllllll}\text { [18] EPİAŞ, } & \text { Şeffaflık } & \text { Platformu } & 4 & 10 & 2019 . & \text { [Çevrimiçi]. } & \text { Available: }\end{array}$ https://seffaflik.epias.com.tr/transparency/piyasalar/gop/ptf.xhtml.

[19] Enerji Atlası, Enerji Atlas1 410 2019. [Çevrimiçi]. Available: https://www.enerjiatlasi.com/haber/elektrik-uretimindekarbon-salinimi. 